\title{
Research on the Effect of Chorus Teaching and Activity on Students' Overall Cultivation
}

\author{
Han Mei \\ College of Music \\ JiMei University \\ Xiamen, China \\ gellever@163.com
}

\begin{abstract}
Choral singing is a compulsory course and an important art practice activity in the music curriculum of primary and middle schools. In the process of teaching and practice, chorus activities play an important role in cultivating students' collective consciousness, breaking through individual limited ability and improving their comprehensive quality. The paper explains how to make use of the methods and techniques of chorus teaching and activities from many aspects and angles, and how to use chorus art to play an effective role in the overall development of students.
\end{abstract}

Keywords-Chorus teaching; Chorus art; Ability training; Comprehensive development

\section{INTRODUCTION}

It is pointed out in the Music Curriculum Standard of Fulltime compulsory Education (2011 Edition) that singing class is the basic content of music curriculum in primary and secondary schools, and it is also a form of expression that students are most willing to participate in [1]. At the same time, singing skills should be combined with singing practice activities [2]. To strengthen and attach importance to the teaching of chorus, students can gradually accumulate experience of singing in cooperation with others, which is an effective way to cultivate students' ability of communication and cooperation, to develop innovative ability and to develop logic of thinking [3]. Nowadays, as an important measure to promote quality education in an all-round way, chorus art has its unique musical participation, teamwork and emotional expression, so that students' ability to set up a correct aesthetic sense has been improved accordingly [4]. Physical and mental as well as intellectual can achieve common development. Therefore, it can be said that choral activities in the area of education to achieve "with more than one stone."

\section{DIFFERENCES OF INDIVIDUAL STUDENTS IN CHORUS TEACHING}

Chorus is a collective activity in which students more or less communicate with others during rehearsals. Individual differences are also revealed during rehearsals, such as differences in musical skills and personality.

The students with weak musical skills often express themselves inaccurately in the aspects of tone, rhythm, musical emotion and so on in chorus training. This is a common and relatively difficult problem in chorus teaching, which often affects the final presentation of chorus works. Differences in individual musical skills allow students to naturally compare themselves to their peers, realized that "I can't sing well", "tone-deaf" and so on. It feels pressured and often feels ridiculed by others and shows a feeling of inferiority. The chorus teaching in the school is faced with all the students, the aim is to make all the students get common development .Therefore, when teachers are faced with this situation, they need to provide appropriate psychological guidance to students, patience training in individual musical skills, and mutual "interaction" among students so that they can feel the love and not given up from the collective [5]. Enhance students' collective consciousness and sense of responsibility.

Teachers should also pay more attention to students with outstanding personality. For example, introverted students, who appear timid in chorus, speak little, sing with little or no voice, slow or ignore the teacher's instructions. Weak communication skills, poor sense of cooperation, lack of collective sense. Over time, students not only cannot get their due development in chorus teaching, but also have a relatively weak ability in their daily study, which has a certain degree of influence on their correct outlook on life and values. For students with an introverted and isolated personality, teachers need to lead them into the collective in the teaching of chorus. They can lead the chorus training or be in charge, so that the students can feel deeply that they are part of the group. And needed by this collective [6]. In order to stimulate the student's sense of responsibility, at the same time to exercise the students' courage and the ability to communicate and cooperate.

With age, some students are reluctant to follow the advice of others. Students with extremely active personality are often eager to express themselves. In chorus training, they are often shown as loud volume, outstanding timbre and disobeying the teacher's command, "singing on their own" and so on. There is obvious disharmony because of one or more students. Most of these students lack a sense of cooperation because they are eager to show themselves. The teacher can lead them to speak correctly and let the student try to supervise and manage other students to obtain the unity of sound. At this time, the student may realize that he or she is "out of sync" with others while supervising other companions, and he or she will lead by example and exert his personality. 


\section{THE SELECTION OF WORKS IN CHORUS TEACHING}

The most intuitive feeling that the chorus art presents to the audience in the end comes from the work itself. Kodaly, a famous Hungarian educator, believes that it is essential to establish a national way of thinking in music education, to strengthen the emotion of the nation and to accumulate the music language of the nation. The main means of music education in singing is to pay more attention to chorus teaching In the selection of teaching materials, domestic excellent music is the first choice, followed by foreign classic works. This cultivates the students' appreciation ability, develops the Chinese national spirit, establishes cultural self-confidence, and at the same time absorbs and understands the excellent cultures abroad, and realizes the integration of multiculturalism in choral teaching. Secondly, adapting measures to local conditions and teaching students in accordance with their aptitude should also be considered. The selection of choral works also requires the use of regional cultural advantages, combining with the local cultural characteristics, such as local folk style, local language works. Strengthening students' study of history and humanistic knowledge, and in a conscious manner, this has played a very good role in promoting and inheriting the culture of the region [7]. Students have individual differences, in the initial selection of choral training works need to be suitable for most students, gradually from easy to difficult, from shallow and deep. The purpose of school choir teaching is not to achieve a high level of singing or performing, therefore, the selection of the works should not be too high in the technical requirements, and should be suitable for the students ' physical and mental development, and conform to the aesthetic interest of the students.The choice of style should be diverse, such as lively, cheerful, passionate, affectionate and unforgettable and so on. Students use different styles of works to express different emotions, and they will also be helpful for the construction of emotional attitudes. In addition, in order to increase students' interest in choral art and to be more proactive in participating in the chorus, they should also choose works that students like and are interested in. For example, appropriate addition of excellent pop songs is also a good choice.

\section{THE APPLICATION OF BODY RHYTHMS IN CHORUS TRAINING}

Junior and middle school is an important stage for children to grow up, is the most easy to improve cognitive ability, but also the most receptive period. As an important teaching method of chorus teaching both at domestic and international, it requires students to participate in chorus activities together to achieve the common and harmonious development of body and mind.

First, body rhythm can help students to better sense music. The most important thing in chorus teaching is to enable students to experience the music itself, cannot use too complex and difficult to coordinate the action. Different rhythms in rhythm can cause the body to rise from basic physiological induction to a high level of emotional response. Swiss music educator Darcros believes that physical movement includes all the basic elements of sound and emotional response. The reaction to emotion is the essence of music. The understanding of music is an emotional process, which evokes people's musical instinct through the combination of body and music, cultivates the students' musical sensibility and quick reaction ability, and then enables the students to gain experience and the ability to express music emotion and emotion.

Second, body rhythm can help students improve their sense of collective cooperation. Petrovsky, a famous psychologist in the former Soviet Union, pointed out that the teenagers in this period were in "transition period", "difficult period" and "crisis period" because of their psychological characteristics. And very eager to establish a harmonious and stable relationship with their peers and adults to reflect their own value; and hope to know how others evaluate themselves, so as to evaluate and guide themselves. In choral activities, students can adjust their breathing patterns and sounds to their best in the rhythm of body limbs due to physical relaxation and mental concentration. Students will not only imitate the teacher, but also be influenced by other students. Unobtrusively strengthened the communication between students and teachers, students and students. Therefore, under the teacher's correct guidance and encouragement, students' individual abilities can transform and absorb each other and promote each other, which can achieve the optimization of chorus teaching and enhance the effect of group consciousness.

Third, body rhythm can broaden students' imagination and logical thinking. Students in their teens showed self-esteem and the ability to think independently, their self-awareness gradually increased, their emotional diversity began to emerge, and they had a certain sense of the beauty of music. The expression of music also has its own independent views. The use of body rhythm in chorus teaching, teachers cannot be a single "leader" and "initiator", cannot blindly ask students and teachers to do the same action, but not too much emphasis on the difficulty of action. Teachers must change the rhythm form flexibly according to the students' overall ability and different songs, which can solve the problem of attention loss. Teachers can also let students according to their own ability and the experience of music emotion, set the situation, create action, enrich the content of songs. To satisfy the development of personality psychology, to improve the students' logical ability of thinking and to complete the pleasant experience of body and mind at the same time [8].

\section{The CONSTRUCtion OF SPIRITUAL CiVILIZATION IN CHORUS ACTIVITIES}

The chorus art is embodied in its collective practice. The practice described here not only requires students to complete the choral teaching in the classroom, but also should step out of the classroom, step out of the campus, and participate in the construction of the campus and social culture. Only by guiding students to actively participate in choral practice can they truly experience music, and only by combining choral activities with our society and more human activities can we gain more music culture. The development of human culture cannot lack an important part of music, music also belongs to everyone. So it is necessary to make music art serve the whole human society better. Such as regular campus choral activities, parents' public viewing meetings and choral competitions; participate in some social stage performances, public welfare performances and so 
on. In the ancient Confucian thought of etiquette and music, there is a philosophical thought of "Changing the style and changing the customs, no one better than music". It shows that music can expand the good social atmosphere, and the singing forms of all ancient times in China occupy a decisive position in music. It is also the easiest method to participate in chorus, which can influence the most people to access truly valuable music. That is to say, choral art has the transmission and appeal that other art forms do not have, and it can display the social spirit to the greatest extent. Undoubtedly, it has strong practical significance and social driving force. Passing truth, virtue, and beauty through choral events is one of the important channels for students to participate in the construction of social spiritual civilization. In the practice of choral art, students participate in social services with a small singing experience in order to enrich campus culture, improve the artistic atmosphere of the whole campus, and spread positive spiritual concept to the society. From this perspective, choral activities have a positive effect on students' sense of social responsibility and social awareness.

\section{THE COMPREHENSIVE ARTISTIC EXPRESSION IN CHORAL ACTIVITIES}

Chorus is a combination of audiovisual art, because it is bound to be associated with other disciplines of art, it also reflects the fusion of multiculturalism [9]. Throughout the history of music, choral art is one of the oldest forms of art in the world's music culture; the Western chorus activity from ancient Greek drama civilization has formed a form of joining poetry and dance. In the period of the peak romanticism in the development of singing art, the close integration of music with poetry, literature, dance, painting, and operas was emphasized. Both show that music is not a single form of art, but needs to be expanded to a wider range of fields. Musicians are also committed to the perfect combination of literature and a variety of arts; the romantic choruses played an irreplaceable role in the opera and enhance the drama of conflict in the works. Modern western choral activities and musical teaching methods also require the combination of music, poetry, drama and dance to form a comprehensive art form. Looking back at the history of Chinese music, according to <Lu's Spring and Autumn Music $>$,'In Getian's music, three people hold oxtails and sing in dance."<The Canon of Yao> mentions:" Poetry expresses will, and singing expresses language." It also shows the unity of chorus and dance in The Zhou Dynasty's $<$ Dawu $>$. From this we can see that in ancient Chinese primitive music and dance, there has been an artistic expression of this combination of music, poetry and dance. In particular, the development of music art to the Tang Dynasty, the art forms of song, dance, music and music have reached unprecedented prosperity. Emperor Li Longji of the Tang Dynasty also wrote the '"'Glamorous Feather Music", which is famous to this day. Song and Yuan Dynasty miscellaneous Zaqu, Yuan opera, Songs and Dances, and during the Ming and Qing Dynasties, $\mathrm{Li}$ Yu's record of singing:" singing songs should have feelings." You can't sing without heart, there is music in the mouth and there is no music on the body"... There are many such records, and it can be seen that the diversity and comprehensiveness of singing in the form of music expression.
With the progress of human civilization, in order to enrich people's growing spiritual and cultural needs, literature, art and other disciplines are constantly merging and developing together. Language is the best way to express your heart, choosing harmonious and literary choral works, from the aspect of consciousness; it cultivates the aesthetic consciousness of students. Dances and theater performances can express the perception of music with a more visual effect, and breaking the rigid state of the stage that only sings. And deepening students' understanding of musical works further enriches the connotation of the works and is more expressive in terms of form. Playing instrumental music in chorus can develop students' various artistic talents, improve their artistic accomplishment and enrich their artistic emotional experience. The use of chorus in a variety of art forms, a variety of artistic forms used in music, but also reflects the requirements of China's art curriculum standards for the development of student art in a comprehensive and harmonious development.

\section{CONCLUSION}

Although there are still some problems in chorus teaching both in China and abroad, and some problems have not been solved for a long time, while others have been gradually reflected in the development of chorus teaching, but put aside the problem, as far as its educational function is concerned, choral art plays an overall guiding and improving role in the development of human beings. Especially in the teen age, which is the easiest phase to shape personality and establish emotional attitudes and values, we should take the opportunity to create a relaxed and pleasant music atmosphere for the children, and cultivate the sentiment of beauty. Through choral activities, children's interest in music and arts is stimulated, so as to develop the ability to cultivate life-long learning, and make them become integrated and innovative talents of the new generation and the advancement of society. Children can recognize the meaning and value of music brought to themselves, others, and even the entire human society. The world will also be more beautiful for children who love music and are willing to contribute to music.

\section{ACKNOWLEDGMENT}

This research was financially supported by the 2015 Hainan Education Science Research Topics of the 12th Five-Year Plan (No.QJY1251536).

\section{REFERENCES}

[1] Weiwei Liu. Study on Chorus Teaching in Middle School Music Education[J]. Art Science and Technology,2013,(02):216.

[2] Jia Zhu. Research on the School-Enterprise Cooperation and the Training of Applied Talents in Music Performance of Applied Marine University[J]. Advances in Economics, Business and Management Research. 2017, vol. 50:16-19.

[3] Xiaowei zhong. On the Role of Chorus Teaching in School Quality Education[J]. Journal of Jiang xi Institute of Education,2000, 21(02):86$88+1$.

[4] Jia Zhu. Research on the Practice of Talent Cultivation of Applied Undergraduate Music Performance Based on School-Enterprise Cooperation[C]. DEStech, 2017 International Conference on Education Innovation and Economic Management (EIEM2017), pp:43-47. 
[5] Chuanying Kuang. Talking about the Cultivation of the Spirit of Cooperation in Chorus Teaching[J]. Yellow River of the Song,2007, (02):60-63.

[6] Xiao Pu,Lingxia Wang. Middle School Chorus Teaching Cultivates Students' Art Accomplishment [J]. Seek Guide,2015,(14):115-116.

[7] Jia Zhu. The research and practice of the training mode of local university music performance professionals[J]. Advances in Intelligent Systems Research. Vols. 129 (2016) pp 285-290.
[8] Shenggui Wang. On the Enlightenment of Kodaly Teaching Method in Chorus Teaching[J]. Beauty,2011,(10):89-90.

[9] Jinjin Du. Study on Chorus Teaching Strategies in Primary and Middle School Music Classes[J]. The World of Music,2011,(04):10-13.

Qiu ling Qin. The Ways and Methods of Cultivating Aesthetic Interest in High School Chorus Teaching[J]. Art,2009,(01):90-91. 